S sciendo

\title{
A Defence of Fregean Propositions
}

\author{
Massimiliano Vignolo \\ Università di Bologna
}

Disputatio Vol. 2, No. 21

November 2006

DOI: $10.2478 /$ disp-2006-0013

ISSN: 0873-626X 


\title{
A defence of Fregean propositions
}

\author{
Massimiliano Vignolo \\ Università di Bologna
}

\begin{abstract}
Stephen Schiffer 2003 presents six arguments against the Fregean model of propositions, according to which propositions are (a) the referents of that-clauses and (b) structured entities made out of concepts. Schiffer advances an alternative view: propositions are unstructured pleonastic entities. My purpose is to argue in favour of the main tenets of the Fregean model by countering each of Schiffer's arguments and sketching the guidelines for a theory of concepts as basic components of propositions.
\end{abstract}

1. Schiffer (2003: 24-27) presents six arguments against the Fregean model of propositions. The Fregean model holds three main theses:

(A) That-clauses are singular terms referring to propositions.

(B) Propositions are structured entities made out of the referents of the expressions forming the that-clauses and the syntactic structure of those clauses.

(C) Expressions occurring in that-clauses have concepts ${ }^{1}$ as their referents.

Schiffer attacks the Fregean model by the following arguments:

(1) We lack a theory of concepts as basic components of propositions.

(2) The Fregean model does not explain how propositions get their truth conditions.

(3) There are cases where it seems that certain singular terms occurring in that-clauses cannot but refer to their ordinary referents.

(4) The Fregean model generates a hierarchy of concepts: concepts, concepts of concepts, concepts of concepts of concepts and so on. It is to be explained what such concepts are and what it is to grasp them.

(5) Sometimes reference to concepts as building blocks of propositions seems highly implausible, because it implies that there are concepts shared by most, if not all, thinkers.

(6) The sixth argument goes like follows:

\footnotetext{
${ }^{1}$ In this paper I use 'concept' as synonymous with 'sense'.
}

Disputatio, Vol. II, No. 21, November 2006 
(i) If the Fregean semantics is correct, then (a) 'Fido' occurs in 'Ralph believes that Fido is a dog' as a singular term whose referent is a concept of Fido.

(ii) If (a), then the following inference (Inf) is valid:

(Inf) Ralph believes that Fido is a dog $\therefore \exists \mathrm{x}(\mathrm{x}$ is a concept \& Ralph believes that $\mathrm{x}$ is a $\mathrm{dog})$.

(iii) But the inference is not valid; given the truth of the premise, the conclusion is also true only in the unlikely event that Ralph mistakes a concept for a dog.

(iv) $\therefore$ The Fregean semantics is not true.

In what follows I will try to counter each of these arguments. I will start commenting on argument (6), then arguments (4), (1), (3), (5) and (2) in this order.

2. In this section I will respond to argument (6). My first remark is that the premise of ( $\mathrm{Inf})$ is ambiguous. It allows for a de dicto reading and for a de re reading. My claim is that in both cases argument (6) is not sound. If we construe the premise of (Inf) as a de dicto belief, then step iii) is false. If we construe the same premise as a de re belief, then step i) is false.

If we construe the premise as a de dicto belief, then 'Ralph believes that Fido is a dog' is true if and only if Ralph stands in the believing relation to the proposition that Fido is a dog. According to the Fregean model, this proposition is made out of the concept of Fido and the concept of being a dog. Accordingly, the logical form of the premise of (Inf) is

$$
\operatorname{Bel}\left(\text { Ralph, }\left\langle\mathrm{C}_{\text {Fido }}, \mathrm{C}_{\text {being a dog }}\right\rangle\right)
$$

The logical form of the conclusion of (Inf) is

$$
\exists \mathrm{x}\left(\mathrm{x} \text { is a concept and } \mathrm{Bel}\left(\mathrm{Ralph},\left\langle\mathrm{x}, \mathrm{C}_{\text {being a dog }}\right)\right)\right. \text {. }
$$

The conclusion is true if and only if there is a concept that, together with the concept of being a dog, forms the proposition that Ralph believes. In quantifying in that-clauses of de dicto beliefs, variables range over concepts. Therefore, according to the Fregean model, if it 
is true that Ralph believes de dicto that Fido is a dog, it is true that there is a concept that, together with the concept of being a dog, forms the proposition that Ralph believes. The advocate of the Fregean semantics can reply to Schiffer's objection by the following counter-argument:

$\left(i^{*}\right)$ If the Fregean semantics is correct, then (a) 'Fido' occurs in 'Ralph believes that Fido is a dog' as a singular term whose referent is a concept of Fido.

(ii*) If (a), then the following inference (Inf*) is valid:

(Inf*) Ralph believes that Fido is a dog

$$
\therefore \exists \mathrm{x}\left(\mathrm{x} \text { is a concept and Bel(Ralph, }\left\langle\mathrm{x}, \mathrm{C}_{\text {being a dog }}\right)\right)
$$

(iii*) The inference is valid.

(iv*) Schiffer's argument is not sound.

Matters are different if we construe the premise of (Inf) as a de re belief. A de re belief is a two place relation between a subject and the object he thinks of. By quantifying in that-clauses of de re beliefs, variables range over the ordinary referents of expressions, and not over concepts. Construed as a de re belief, the premise

Ralph believes that Fido is a dog

turns into

(*) Ralph believes of Fido that it is a dog

whose logical form is

Believing to be a $\operatorname{dog}($ Ralph, Fido)

In $(*)$ the proper name 'Fido' refers to Fido and not to the concept of Fido. In (**) the variable ' $x$ ' ranges over things that are ordinary referents of singular terms:

(**) $\exists \mathrm{x}$ (Ralph believes of $\mathrm{x}$ that it is a dog).

And the logical form of $(* *)$ is

$\exists \mathrm{x}$ (Believing to be $\operatorname{dog}($ Ralph, $\mathrm{x}))$. 
The advocate of the Fregean model is not committed to denying that in $(*)$ 'Fido' refers to Fido. He claims to have the resources to spell out the believing-to-be-a-dog relation between Ralph and Fido in terms of a de dicto belief: Ralph believes of Fido that it is a dog if and only if the proposition $\left\langle\mathrm{C}_{\text {Fido }}, \mathrm{C}_{\text {being a dog }}\right\rangle$ is a mode of presentation (MP) of the state of affairs $\langle$ Fido, being a $\operatorname{dog}\rangle$ and Ralph believes such proposition. The logical form of the sentence 'Ralph believes of Fido that it is a dog' is

$$
\left.\operatorname{MP}\left(\left\langle\mathrm{C}_{\text {Fido }}, \mathrm{C}_{\text {being a dog }}\right\rangle,\langle\text { Fido, being a dog }\rangle\right) \text { and Bel(Ralph, }\left\langle\mathrm{C}_{\text {Fido }}, \mathrm{C}_{\text {being a dog }}\right\rangle\right)
$$

The logical form of the sentence ' $\exists x($ Ralph believes of $x$ that it is a $\operatorname{dog})^{\prime}$ is

$$
\exists \mathrm{x} \exists \mathrm{y}\left(\mathrm{MP}\left(\left\langle\mathrm{y}, \mathrm{C}_{\text {being a dog }}\right\rangle,\langle\mathrm{x} \text {, being a dog }\rangle\right) \text { and } \operatorname{Bel}\left(\text { Ralph, }\left\langle\mathrm{y}, \mathrm{C}_{\text {being a dog }}\right\rangle\right)\right)
$$

This is David Kaplan's 1969 proposal to account for de re beliefs in terms of de dicto beliefs, which has been attacked by Tyler Burge 1977. Burge's main objection to Kaplan is that de re beliefs are irreducible to de dicto beliefs. The reason why Burge thinks so is that in order to achieve such reduction, we would need Fregean senses expressed by demonstratives and indexicals and, according to Burge, there cannot be such senses. I agree with Burge that we need such senses, but I disagree with him on the impossibility of having them². Here I will not argue in defence of Kaplan's proposal, but only stress the point that Schiffer's argument is not effective. It is true that if Burge is right, then the reading of 'Ralph believes that Fido is a dog' as a de re belief poses a problem to the Fregean model. But Schiffer's argument per se is silent on whether Burge's criticism of Kapkan's proposal succeeds.

3. Schiffer's argument (4) points at the difficulty posed by the hierarchy of concepts. I quote Schiffer's passage:

According to the Fregean, whenever you refer to anything, you do so under some particular concept of that thing. What then is the concept under which you are referring to a concept of George Eliot in uttering the token

\footnotetext{
${ }^{2}$ For a defence of Fregean senses expressed by demonstratives and indexicals see Evans 1982, McDowell 1984, Künne 1997.
} 
of 'George Eliot' in your utterance of (8) (= 'I met a high school English teacher who actually believes that George Eliot was a man') and what then is the concept under which you are referring to a concept of the property of being a man in uttering the token of 'man' in your utterance of (8)... I dare say it is clear that no one can say what concepts are the referents of 'George Eliot' and 'man' in (8) or what the concepts are under which one is referring to those concepts (Schiffer 2003: 25).

The argument has two parts. The first part says that we do not know of what building blocks the proposition referred to by 'that George Eliot was a man' is made out. This part of the argument repeats the objection that we do not know what concepts are, since we lack a proper theory of them. The second part of the argument raises the objection that the Fregean model generates a hierarchy of concepts: concepts, concepts of concepts, concepts of concepts of concepts and so on. If we do not know what concepts are at the first level, still less we know what they are at the higher levels. The objection moves from a principle of the Fregean model:

(P) Whenever we refer to something, we do it by grasping a concept under which that thing falls.

Consider the following sentence:

(f) John believes that George Eliot was a man.

In (f) 'George Eliot' refers to the concept of George Eliot. Then, Schiffer argues, a speaker refers to the concept of George Eliot by asserting (f). But, according to $(\mathrm{P})$, he must grasp a concept of the concept of George Eliot. Given that propositional attitudes sentences might be iterated indefinitely many times (at least from the logical point of view, if not from the psychological one), the hierarchy of concepts is generated.

Philosophers have proposed two solutions to the hierarchy problem. The first solution consists in denying that the Fregean model is committed to the hierarchy of concepts. The second solution consists in accepting the hierarchy and showing that it is not troublesome. Philosophers who endorse either solution hold that in order to understand the concept expressed by an expression occurring in an indirect context, it is sufficient to understand the concept it expresses in direct contexts and the syntactic structure of the whole sentence in 
which it occurs. So, both solutions are conditional on there being a theory of concepts expressed in direct contexts and of our understanding of them. In section $\S 4$ I will argue that we can have such theory. Before that, I wish to rehearse the guidelines of the mentioned solutions to the hierarchy problem.

The first solution was suggested by Michael Dummett (1973: 267-8). Dummett says that we can adjust Frege's theory so as to avoid the hierarchy of concepts. The adjustment required is provided by the following principles:

(1) A word always expresses its customary sense.

(2) A word in an indirect context refers to its customary sense $e^{3}$.

So, the occurrence of 'George Eliot' in (f) expresses its customary concept and refers to it as well. No hierarchy is generated at all. Provided that we know what the concept expressed by 'George Eliot' in direct contexts is and what it is to understand it, no further difficulty is posed by explaining its occurrences in indirect contexts. More recently Christopher Peacocke has advocated this solution. He proposes the Redeployment Claim (Peacocke 1996: 131-2):

The sense of a word occurring in contexts not involving propositional attitude construction is the same sense which is redeployed as that word's sense when the word occurs within the scope of propositional attitude verbs.

The core idea behind the Redeployment Claim is that the most direct way of thinking of a proposition referred to by a that-clause is to entertain that same proposition, that is to reuse, to redeploy it.

We can draw a distinction between two ways of referring to propositions and their building blocks: a way that demands awareness of referential intentions and a way that does not. One might intend to refer to a concept by using a certain expression, for example 'the concept expressed by 'oritteropo' in Italian'. In this sense, one might refer to a concept without mastering that concept. For example, an English speaker might believe that the concept expressed by 'oritteropo' in Italian is identical to the concept expressed by 'oryctérope' in French (maybe because a trusty friend has told him), even though he

\footnotetext{
${ }^{3}$ See also Parsons (1981: 43).
} 
does not master such concept (assume he does not master the concept expressed by 'aardvark' in English).

The other way to refer to propositions and their building blocks is by using expressions in indirect contexts. The ascriber does not need to be aware of referring to a proposition when he ascribes a certain propositional attitude to John by asserting (f). In other words, the ascriber does not need to know explicitly the theoretical reconstruction of the truth-condition of (f). All the ascriber is required for referring to the proposition $\left\langle\mathrm{C}_{\text {Geroge Eliot }}, \mathrm{C}_{\text {being a man }}\right\rangle$ in asserting (f) is to master the concepts $\mathrm{C}_{\text {Geroge Eliot }}$ and $\mathrm{C}_{\text {being a man }}$ and the syntactic structure of (f). He is not required to grasp any concepts under which the concepts $\mathrm{C}_{\text {Geroge Elot }}$ and $\mathrm{C}_{\text {being a man }}$ fall. For example, in asserting (f), Mary ascribes the belief that George Eliot was a man to John. According to the Fregean model, the truth condition of (f) involves the concept of George Eliot: ( $f$ ) is true if and only if John stands in the believing relation to the proposition $\left\langle\mathrm{C}_{\text {Geroge Eliot }}, \mathrm{C}_{\text {being a man }}\right\rangle$. We do not need any concept of concept in order to specify the truth-condition of (f). We do not need any concept of concept in order to construct the proposition expressed by (f) either. The proposition expressed by (f) is made out of the concept of John, the concept of the believing relation and the proposition $\left\langle\mathrm{C}_{\text {Geroge Eliot }}, \mathrm{C}_{\text {being a man }}\right\rangle$. We can represent such proposition as $\left\langle\mathrm{C}_{\text {believing }}, \mathrm{C}_{\text {John }},\left\langle\mathrm{C}_{\text {Geroge Eliot }}, \mathrm{C}_{\text {being a man }}\right\rangle\right\rangle$. To grasp this proposition Mary needs to master the concepts $C_{\text {believing }}, C_{\text {John }}$, $\mathrm{C}_{\text {Geroge Eliot }}, \mathrm{C}_{\text {being a man }}$ and to know the syntactic structure of (f). Even if we form propositional attitude sentences more and more complicate, we are not forced to generate any hierarchy of concepts.

In sum, the problem of the hierarchy of concepts arises from too a strict reading of $(\mathrm{P})$ that overlooks the difference between the two ways of referring to propositions and their building blocks. If we are aware of our referential intentions in using an expression to refer to a thing, then we must grasp a concept under which the thing referred to falls. This is the case of our referring to concepts or propositions by using expressions like 'the concept expressed by 'oritteropo' in Italian' and 'the proposition expressed by the first sentence of Joyce's Ulysses'. But most speakers are not aware of their referential intentions when they refer to concepts and propositions in indirect contexts. In these cases, then, they do not need to grasp higher-order concepts under which the concepts referred to fall. This, of course, does not mean that words in indirect contexts do not express concepts. They express their ordinary concepts, namely the same con- 
cepts they express in direct contexts. Hence our referring to a concept in an indirect context goes through our grasping a concept, but this is the same concept we refer to.

The second solution to the hierarchy objection consists in showing that the hierarchy of concepts is not harmful. Tyler Burge 2005 has recently advocated this solution. I will not discuss the advantages and the disadvantages of Burge's solution in respect of the former. Rather, I wish to point out that the second solution shares with the first one the view that in order to understand the occurrence of a word in an indirect context it is sufficient to grasp the concept it expresses in direct contexts and the syntactic structure of the sentence in which it occurs. This proposal resembles the Redeployment Claim advanced by Peacocke and if it succeeds, then there is no particular difficulty about learning even a potentially infinite hierarchy of concepts and in understanding them.

The threat posed by the hierarchy is twofold. On the one hand, there is the problem of explaining what concepts are at the higher levels. On the other hand, there is the problem that if we introduce the hierarchy, languages turn out to be unlearnable ${ }^{4}$. There are two key notions in Burge's solution. The first is the notion of 'the canonical concept function'. The canonical concept function is a function from a concept at level $n$ to the concept at level $n+1$ that determines the concept at level $n$. Let us introduce the one-place functional expression ' $\Phi$ ' to stand for the canonical concept function. Then, for example, if $\mathrm{C}_{\text {Geroge Eliot }}$ is the concept expressed by 'George Eliot' in direct contexts, then $\Phi\left(\mathrm{C}_{\text {Geroge Eliot }}\right)$ is the concept expressed by 'George Eliot' in first level indirect contexts like (f). The proposition expressed by (f) is $\left\langle\mathrm{C}_{\text {believing, }}, \mathrm{C}_{\text {John }},\left\langle\Phi\left(\mathrm{C}_{\text {Geroge Eliot }}\right), \Phi\left(\mathrm{C}_{\text {being a man }}\right)\right\rangle\right\rangle$. Of course $\Phi$ can be iterated. If we introduce canonical names of first level concept, like ' $\mathrm{C}_{\text {Geroge Eliot }}$ ', we can construct canonical names for higher level concepts, like ' $\Phi\left(\mathrm{C}_{\text {Geroge Eliot }}\right)$, ' $\Phi\left(\Phi\left(\mathrm{C}_{\text {Geroge Eliot }}\right)\right.$ ' and so on. The canonical concept function establishes a backward road from concepts to the higher level concepts that determine them. The second key notion is the Principle for canonical names of concepts (Burge 2005: 174):

Principle for canonical names of concepts: the canonical name of a concept can be understood only if the concept that it names is understood.

\footnotetext{
${ }^{4}$ See Davidson 1965.
} 
This principle states a necessary condition for understanding higher level concepts: the second level concept expressed by a canonical name can be understood only by understanding the concept that it determines. For example, to understand the concept expressed by ' $\mathrm{C}_{\text {Geroge Eliot }}$ ' one need to understand the concept expressed by 'George Eliot'. And to understand higher level concepts in the hierarchy, one must understand iterations of indirect contexts signaled in English by iterations of that-clauses. We arrive at a necessary and sufficient condition for understanding higher levels concepts: it is necessary and sufficient for understanding higher levels concepts that one (i) understands the ordinary concepts, (ii) understands a finite number of canonical names of those ordinary concepts, (iii) understands levels of embeddings, (iv) understands principles for functionally composing canonical names of concepts of complex expressions from canonical names of the concepts of simple expression (for example $\Phi\left\langle\mathrm{C}_{\text {Geroge }}\right.$ Eliot, $\left.\left.\mathrm{C}_{\text {being a man }}\right\rangle=\Phi\left(\mathrm{C}_{\text {Geroge Eliot }}\right) \wedge \Phi\left(\mathrm{C}_{\text {being a man }}\right)\right)$.

As noted, the first and the second solution share the view that to understand an expression in an indirect context consists in understanding the concept it expresses in direct contexts and the syntactic structure of the whole sentence in which it occurs. According to the second solution this amounts to understanding and referring to a potentially infinite hierarchy of concepts, whereas according to the first solution this amounts to understanding and referring to concepts of the same level. Even if one prefers the second solution, no more difficulty is left in learning a language committed to a potentially infinite hierarchy of concepts and in saying what higher levels concepts are, provided we know what ordinary concepts are.

I turn to answer Schiffer's objection that we lack a proper theory of concepts and, therefore, we do not know what ordinary concepts are.

4. By argument (1) Schiffer denounces the lack of a theory of concepts as basic components of propositions. He writes:

There is the illusion that we know what the components of Fregean propositions are, because the Fregean has borrowed familiar terms 'concept', 'mode of presentation', 'way of thinking', and so on - to stand for those components; but it is an illusion, because, as we have already noticed, in her theory these terms are technical terms meaning not a whole lot more than the basic components of propositions, assuming those components are not the object and properties our beliefs are 
about. The Fregean owes a more complete specification of what concepts, and therewith Fregean propositions are (Schiffer 2003: 24).

Schiffer holds that the notion of concept is functionally defined as whatever satisfies the Frege's constraint ${ }^{5}$. This constraint says that a rational person $\mathrm{x}$ may believe and disbelieve of a certain thing or property $y$ that it is such and such only if (i) there are distinct concepts $\mathrm{C}$ and C' such that $\mathrm{x}$ believes $\mathrm{y}$ to be such and such by entertaining $\mathrm{C}$ and disbelieve $\mathrm{x}$ to be such and such by entertaining $\mathrm{C}^{\prime}$ and (ii) $\mathrm{x}$ fails to realise that $\mathrm{C}$ and $\mathrm{C}^{\prime}$ are concepts of one and the same thing or property. Something is a concept only if it plays this cognitive role. To ask what concepts are is just to ask what things play this role. In this section, I will argue that we can construct a theory of concepts on certain grounds that Schiffer himself seems to admit. And from this theory we can extract identity criteria for concepts and consequently for propositions as structured entities made out of them.

Schiffer (2003: ch. 2) maintains that propositions are pleonastic entities, which are the unstructured referents of that-clauses. A striking feature of pleonastic entities, he argues, is how easily we are committed to their existence. Their existence is secured by inferences that take one from premises in which no reference is made to propositions to conclusions that contain singular terms referring to them. He calls the inferences of this kind 'something-from-nothing transformations ${ }^{6}$. As to propositions, Schiffer says, our linguistic practice is involved in inferences like the following:

from the premise

(p) Fido is a dog

to the conclusion

(p*) that Fido is a dog is true

(p*) contains the that-clause 'that Fido is a dog', which refers to the proposition that Fido is a dog. In general, from every true indicative sentence $S$, we can infer the sentence 'that $S$ is true', which contains

${ }^{5}$ Cf. Schiffer (1992: 502; 1994: 282-3).

${ }^{6}$ Cf. Schiffer (2003: 51). 
the that-clause 'that S' referring to a proposition. Propositions, then, form a class of pleonastic entities.

However, the language game we play with that-clauses is not exhausted by the something-from-nothing transformations. We employ that-clause especially in attributions of psychological states like belief. This use of that-clauses turns out to be of particular importance for Schiffer's account of propositions as pleonastic entities. Indeed, Schiffer is pressed to give identity criteria for propositions, even if they are thought of as pleonastic entities. After all, the sentence 'the proposition that Superman flies is true' follows from the sentence 'Superman flies'; but the sentence 'the proposition that Clark Kent flies is true' follows as well. While having the same truthconditions, the proposition that Superman flies and the proposition that Clark Kent flies are different. Why? According to Schiffer, the criteria for the attribution of propositional attitudes enable us to distinguish them. These criteria establish, for example, that Lois believes that Superman flies but disbelieves that Clark Kent flies. Given that the proposition that Superman flies is believed by Lois and the proposition that Clark Kent flies is not, we conclude that they are distinct. When we attribute a belief to a subject, Schiffer says, we do not proceed by individuating the proposition, which is the content of the belief, and then by checking whether the subject believes it. On the contrary, we first verify whether the criteria for the attribution of the belief are satisfied and then we individuate the proposition believed $^{7}$. Given that such criteria justify the attribution to Lois of the belief that Superman flies and do not justify the attribution of the belief that Clark Kent flies, we conclude that the proposition that Superman flies is different from the proposition that Clark Kent flies.

This marks an important difference between the relation of reference for that-clauses and the relation of reference for other singular terms. The logical form of propositional attitudes sentences is the same as the logical form of any sentence formed of a two-place predicate flanked by two singular terms:

$$
\mathrm{t}_{1} \mathrm{Rt}_{2}
$$

When $t_{2}$ is not a that-clause, we need identity criteria for the referents of $t_{1}$ and $t_{2}$ in order to evaluate the truth-value of $t_{1} R t_{2}$. We proceed

\footnotetext{
${ }^{7}$ Cf. Schiffer (2003: 72-7).
} 
by individuating the referent of $t_{1}$, then the referent of $t_{2}$, and finally by determining whether they stand in the $\mathrm{R}$ relation. On the contrary, Schiffer says, when $t_{1} \mathrm{R} \mathrm{t}_{2}$ is a propositional attitude sentence and $t_{2}$ is a that-clause, we reverse the procedure. First we get criteria of evaluation of $t_{1} R t_{2}$ and then we extract identity criteria for the referent of $t_{2}$. The identity criteria of propositions depend on the criteria of evaluation of propositional attitudes sentences. It is because 'Lois believes that Superman flies' and 'Lois believes that Clark Kent flies' are evaluated respectively as true and false that we conclude that the proposition that Superman flies is not identical to the proposition that Clark Kent flies.

Schiffer, then, needs criteria for the evaluation of belief attribution that enable us to individuate propositions. But, given that propositions are 'unstructured but very fine-grained', where could such criteria come from? Very likely, criteria for the evaluation of attributions of beliefs as relations to so fine-grained propositions can only be traced back to linguistic behaviour. For example, Lois will give her assent to 'Superman flies' and will dissent from 'Clark Kent flies'. Schiffer seems to concede this point when he writes:

Ascriptions of belief are attuned to what the person to whom the belief is ascribed would say. A fluent English speaker who is willing to assert 'Superman flies' but unwilling to assert 'Clark Kent flies' counts as believing that Superman flies and not believing that Clark Kent flies (Schiffer 1994: 111).

To sum up, according to Schiffer (1994: 106), propositions are introduced as pleonastic entities by:

(1) Giving singular terms allegedly referring to them (the that-clauses).

(2) Fixing the something-from-nothing-transformations.

(3) Providing criteria for the evaluation of propositional attitude sentences, which ultimately need to be traced back to speakers' linguistic dispositions and determine the criteria of individuation of propositions.

As noted, Schiffer seems to concede that the criteria for the individuation of propositions need to be traced ultimately back to facts pertain-

\footnotetext{
${ }^{8}$ Cf. Schiffer (2003: 84).
} 
ing linguistic behaviour. The point I wish to highlight is that there is a theory that attempts to individuate concepts out of speakers' linguistic dispositions. This is the theory advocated by Paul Horwich $1998^{9}$. According to this theory, to express a certain concept is to adhere to certain basic and explanatorily fundamental patterns of use of linguistic expressions. The concept-constitutive patterns of use are traceable back to speakers' inferential and referential abilities. Each expression expresses the concept it does in virtue of the acceptance conditions of certain sentences containing it. I do not intend to attempt a defence of this theory. Rather, I claim that if we assume that the theory succeeds in fixing the concepts-constitutive patterns of use tracking ultimately facts pertaining linguistic behaviour, then we have all is needed to introduce concepts as abstract entities that enter propositions as their building blocks. But, and this is the point to be stressed, all we need to introduce concepts through this theory does not exceed what Schiffer says it is needed to introduce propositions as pleonastic entities: facts pertaining linguistic behaviour.

We can sketch the guidelines of this theory as follows. Let $\mathrm{w}$ be a linguistic expression and $U$ the property of being governed by certain concept-constitutive uses, we proceed by:

1) Introducing the singular term for the concept expressed by w: 'the concept W'.

2) Stating a biconditional saying what constitutes w's expressing the concept W:

$\mathrm{w}$ expresses the concept $\mathrm{W}$ if and only if $\mathrm{Uw}$.

3) Providing criteria for the individuation of concepts:

the concept $\mathrm{W}$ is identical to the concept $\mathrm{Y}$ if and only if $\mathrm{w}$ and $\mathrm{y}$ have the same constitutive uses.

According to this theory, concepts are constituted by regularities of use of linguistic expressions. The theory, then, allows us to refer to concepts and to individuate them as basic components of propositions. Propositions can therefore be considered as structured entities made out of concepts and syntactic structures. We can have the

\footnotetext{
${ }^{9}$ See also Cozzo 1994.
} 
traditional identity criteria for propositions: two propositions are identical if and only if they have the same components and the same syntactic structure.

In conclusion, Schiffer is committed to the existence of linguistic dispositions that are distinctive of attributions of psychological states like belief. Such dispositions are needed to fix the criteria of evaluation for propositional attitude sentences, which in turn are necessary for the individuation of pleonastic proposition. My conjecture is that these linguistic dispositions involve attitudes towards sentences. But attitudes towards sentences, more specifically dispositions to accept them, are all we need to individuate concepts according to the theory depicted above. Thus, there is on the market a theory of concepts that requires nothing more than Schiffer's theory of pleonastic propositions does, if my conjecture is correct.

5. Schiffer presents argument (3) as follows:

According to my stipulated Fregean, the referent of a term in a belief report's that-clause is a concept of an object or property the belief purports to be about, yet it is obvious that terms in that-clauses often refer to things that are not concepts but are the very things the belief is about. When your husband's brother says to you, 'I believe I am falling in love with you', isn't it obvious that both utterances of 'I' refer to him and that his utterance of 'you', refers to you? (Schiffer 2003: 25).

Schiffer says that when your husband's brother asserts the sentence 'I believe that I am falling in love with you' it is obvious that the indexical 'I', which occurs in the that-clause, has your husband's brother as referent and not a concept of him. Why is it obvious that the indirect occurrence of 'I' refers to your husband's brother? The reason Schiffer has in mind is the same as the one discussed in section $\S 2$. According to him, if expressions refer to concepts in indirect contexts, then we cannot account for the validity of inferences like the following (Schiffer 2003: 35):

I believe that I am falling in love with you

$\therefore \exists \mathrm{x}$ (I believe that $\mathrm{x}$ is falling in love with you)

I have already replied to this objection in section $\S 2$. However, there might be another intuition lurking beneath Schiffer's objection. The intuition that your husband's brother wants to vehicle information 
about himself and not about a concept of him. I want to examine to what extend one might resort to this intuition.

For sure, your husband's brother thinks of himself when he grasps the proposition expressed by (e) 'I am falling in love with you' and speaks of himself when he utters that sentence. Our intuition is that he continues to think of himself when he grasps the proposition expressed by (e*) 'I believe I am falling in love with you' and to speak of himself when he utters that sentence. Apparently, the Fregean model does not need to question this much. The interesting point is to explain what enables your husband's brother to think and speak of himself: he is able to think of himself because the proposition expressed by (e), which he grasps, is formed by concepts and one of them is a concept of him. And he is able to speak of himself because he utters an expression that expresses such concept. But, the truth condition of the proposition expressed by (e*) is that your husband's brother stands in the believing relation to the proposition expressed by (e). Then, Schiffer seems to object, the assertion of ( $\left.\mathrm{e}^{*}\right)$ vehicles information about the attitude of your husband's brother to a proposition. On the contrary, by the assertion of ( $\left.\mathrm{e}^{*}\right)$ your husband's brother wants to speak of his falling in love with you and not of his believing a certain proposition.

My response is that granting that the truth condition of the proposition expressed by $\left(\mathrm{e}^{*}\right)$ is that your husband's brother stands in the believing relation to the proposition expressed by (e) is not to deny that by asserting ( $\left.\mathrm{e}^{*}\right)$ your husband's brother communicates information about him. I suggest that the advocate of the Fregean model might rely on the distinction between content of thought and object of thought. Fregrean propositions are contents of thought. The objects of thought are the state of affairs or Russellian propositions they are about. As concepts determine referents, so Fregean propositions determine states of affairs. Grasping a Fregean proposition is a necessary condition for thinking of a state of affairs. However, to have a content of thought is not a sufficient condition for having an object of thought. There are propositions that are made out of concepts that do not determine anything. For example, the proposition that Pegasus flies. In such cases, entertaining a proposition is to have a content of thought without an object of thought.

The truth conditions of propositional attitude sentences must involve propositions, for propositions are theoretical entities introduced to explain our ability to think about state of affairs. They are 
the relata of propositional attitudes. But to concede this much is not to say that the information communicated by a propositional attitude sentence is totally about a subject entertaining a certain content of thought. The information communicated is also about the object of thought, if any. Indeed, as noted in section $\S 3$, in order to understand a propositional attitude report we need to understand the proposition referred to by the that-clause. In Peacocke's words, we need to redemploy such proposition, no matter whether we prefer the first solution or the second solution to the hierarchy problem. In fact, according to Burge's solution too, we need to understand the concepts at the lowest level in order to understand the concepts at the higher levels. But concepts at the lowest level are the ordinary concepts. And any time we entertain ordinary concepts we think of their referents, if any. Therefore, any time we understand a propositional attitude report, we think of the state of affairs, if any, which the proposition referred to by the that-clause is about.

Accordingly, the proposition expressed by (e) is the content of the belief of your husband's brother. The object of his belief is the state of affairs made out of him, you and the falling in love relation. By asserting ( $\left.\mathrm{e}^{*}\right)$ your husband's brother says that he believes the proposition expressed by (e). But he speaks of the object of his belief as well. Even though the truth-condition of ( $\left.\mathrm{e}^{*}\right)$ is that your husband's brother stands in the believing relation to the proposition expressed by (e), still that proposition is a way of presentation of his falling in love with you. Your husband's brother and we all need to grasp the proposition expressed by (e) in order to understand ( $\left.\mathrm{e}^{*}\right)$. And whenever we grasp such proposition, we think of the state of affairs made out of your husband's brother, you and the falling in love relation. So, the information communicated by the assertion of $\left(\mathrm{e}^{*}\right)$ is also about your husband's brother falling in love with you.

One might react and object that the notion of state of affairs, or Russellian proposition, is extraneous to Frege's doctrine. My answer is that there are Fregean theorists who hold that the notion of Fregean proposition is compatible with the notion of Russellian proposition, when the former is taken as the content and the latter as the object of propositional attitudes. Consider, for example, Edward Zalta (1993: 234) who modifies Frege's view by taking the denotation of a sentence (in direct contexts) to be a Russellian proposition and the cognitive content of a sentence (in direct contexts) a Fregean proposition. After all, given that (i) Fregean propositions are made out of concepts, (ii) 
concepts determine referents and (iii) referents are the building blocks of Russellian propositions, there is a straightforward sense in which Fregean propositions determine Russellian propositions.

Bearing in mind the distinction between content of thought and object of thought, I attempt a diagnosis of Schiffer's feeling of obviousness regarding the 'I believe that I am falling in love with you' case. Schiffer gets the impression that it is obvious that the indirect occurrence of 'I' in ( $\left.\mathrm{e}^{*}\right)$ refers to your husband's brother. I hypothesise that such feeling of obviousness is due to the fact that in cases where we use indexicals in indirect contexts, we feel justified in (i) inferring existential quantification on the indexicals having indirect occurrences and (ii) taking variables to range over ordinary referents. For example, we feel that your husband's brother is justified in inferring:

(e**) $\exists \mathrm{x}$ (I believe that $\mathrm{x}$ is falling in love with you)

As said in section $\S 2$, from the point of view of the logical form, this inference does not pose any threat to the Fregean model to the extent that $\left(\mathrm{e}^{*}\right)$ is given a de re reading and de re attitudes are reduced to de dicto ones in accordance with Kaplan's analysis. Then, to say that your husband's brother is justified in drawing the inference $\left(\mathrm{e}^{*}\right)-\left(\mathrm{e}^{* *}\right)$ requires that we are justified in giving $\left(\mathrm{e}^{*}\right)$ a de re reading. But this is tantamount to saying that we are justified in concluding that the belief of your husband's brother is guaranteed to have an object of thought.

So, the basic idea Schiffer is tackling seems to be that there are cases of propositional attitudes reports, specifically those that involve indexicals in indirect occurrences, such that the contents of thought are guaranteed to determine objects of thought. But in order to preserve this intuition we are not forced to abandon the Fregean model. On the contrary, the Fregean account of concepts expressed by indexicals renders such concepts object-dependent, in the sense that their existence depends on the existence of the objects they are about. It follows that whenever one entertains a Fregean proposition made out of objectdependent concepts, the proposition entertained is guaranteed to determine an object of thought. As a consequence, it allows for a de re reading that makes it possible to quantify on indirect occurrences of indexicals and take variables to range over ordinary referents.

6. Schiffer claims to pose a severe problem to the Fregean model by his argument (5). He writes: 
It is apt to seem that, whatever concepts turn out to be, there are cases where it is implausible to think anything that could be called reference to a concept is going on. An example of such a case is the belief report

Just about everyone who visits New York City believes that it is noisy

which is both true and easily understood, even though, one would think, there is nothing to which the occurrence of 'it' might there refer that could, in any sense, constitute the way in which nearly every visitor to New York thinks of the city (Schiffer 2003: 27).

According to the Fregean model the that-clause 'that it is noisy' refers to a proposition. This proposition is made out of a concept that determines New York City. Hence, the truth of the sentence $(\mathrm{k})$ 'everyone who visits New York City believes that it is noisy' implies that every visitor has a belief whose content is that proposition. And this implies that every visitor thinks of New York City by entertaining the concept that enters that proposition as one of its building blocks. As a consequence, there must be a single concept of New York City entertained by every visitor of the city. Schiffer's objection is that there exists no single concept entertained by everyone who visits New York City.

The first thing to notice is that $(\mathrm{k})$ can be given a de dicto and a de re reading.

The de re reading does not seem to pose any serious difficulty. According to Kaplan's analysis illustrated in section §2, the logical form of $(k)$ is:

$\forall \mathrm{x} \exists \mathrm{y}\left(\mathrm{MP}\left(\left\langle\mathrm{y}, \mathrm{C}_{\text {being noisy }}\right\rangle,\langle\right.\right.$ New York City, being noisy $\left.\rangle\right)$ and (visit(x, New York City $\left.) \rightarrow \operatorname{Bel}\left(\mathrm{x},\left\langle\mathrm{y}, \mathrm{C}_{\text {being noisy }}\right\rangle\right)\right)$.

This analysis leaves the value of ' $y$ ' unspecified. As Zalta (2001: 341) suggests, nothing prevents us from using the variable ' $x$ ' as an index for the variable ' $y$ ':

$\forall \mathrm{x} \exists \mathrm{y}\left(\mathrm{MP}\left(\left\langle\mathrm{y}_{\mathrm{x}}, \mathrm{C}_{\text {being noisy }}\right\rangle,\langle\right.\right.$ New York City, being noisy $\left.\rangle\right)$ and (visit(x, New York City $\left.) \rightarrow \operatorname{Bel}\left(\mathrm{x},\left\langle\mathrm{y}_{\mathrm{x}}, \mathrm{C}_{\text {being noisy }}\right\rangle\right)\right)$.

Now, the values of ' $y$ ' are relative to the values of ' $x$ '. This means that each visitor might have his own idiosyncratic concept through which he thinks of New York City. 
The trouble arises due to the de dicto reading of $(\mathrm{k})$. The logical form of $(k)$ is:

$$
\forall \mathrm{x}\left(\operatorname{visit}(\mathrm{x}, \mathrm{New} \text { York City }) \rightarrow \operatorname{Bel}\left(\mathrm{x},\left\langle\mathrm{C}_{\mathrm{New}} \text { York City }, \mathrm{C}_{\text {being noisy }}\right\rangle\right)\right)
$$

This sentence seems to relate each visitor of New York City to the proposition made out of the concept $\mathrm{C}_{\mathrm{New} \text { York }}$. And this, Schiffer says, implies that $\mathrm{C}_{\mathrm{New} \text { York City }}$ is mastered by each visitor of New York City.

The argument assumes that in order for a subject to have a propositional attitude to a proposition $\mathrm{P}$ the subject must fully master each concept that forms $\mathrm{P}$. But this assumption is no part of the Fregean model ${ }^{10}$. However, the rejection of this assumption requires an argument in favour of two claims:

(1) There is a concept of New York City that is referred to by the indirect occurrence of 'it'.

(2) There is a sort of propositional attitude to the proposition referred to by 'that it is noisy' we can attribute to a subject even if he does not master fully the concept referred to by the indirect occurrence of 'it'.

The concept referred to by the indirect occurrence of 'it' is the concept expressed by the proper name 'New York City' in direct contexts. According to the theory depicted in section $\S 4$, this concept is constituted by the linguistic practice of the expert speakers (maybe the inhabitants of New York City). Of course, it is very unlikely that every visitor of New York City has a full mastery of such concept. However, we can imagine constitutive uses of the proper name 'New York City' with different levels of expertise. Most speakers master only few constitutive uses and defer in their use of the proper name to other members of their linguistic community, who are experts and have a better mastery of the proper name. But this fact does not prevent true attributions of propositional attitudes involving that concept to each visitor of New York. The idea is that the division of the linguistic labour and the deference to experts enable us to ascribe propositional attitudes to propositions even though those propositions are made out of concepts that the ascribee does not master completely.

According to Peacocke (1992: 27-33), two sorts of attributions of propositional attitudes are to be distinguished:

\footnotetext{
${ }^{10}$ I thank an anonymous referee for helpful comments on this point.
} 
(i) fully-mastered;

(ii) deference-dependent.

The truth of a fully-mastered attribution implies that the subject has a full mastery of each concept that enters the proposition as its constituent. By contrast, a deference-dependent attribution is true even when the subject has only a partial understanding of the constituent concepts. So, incomplete understanding of concept does not prevent true attributions of propositional attitudes to propositions made out of such concepts. One might take that the propositional attitudes that satisfy condition (i) to be the primary ones. There would not be propositional attitudes satisfying condition (ii), if there were not propositional attitudes satisfying condition (i). But there is no compelling reason that forces us to assume that the relations denoted by the verbs of propositional attitude satisfy only condition (i).

For sure, we cannot attribute to each visitor of New York City a full mastery of the concept NEW YORK CITY. Still, we can attribute to them some recognitional abilities and some knowledge of the referent of the concept. For example, we can attribute to them the ability to judge the truth-values of sentences like 'this is New York City', 'that is the city I visited last year', 'New York City is a big city', 'New York City is not a lake' and so on. The ability to judge the truth-values of sentences like these is part of the complex of abilities that are constitutive of the concept NEW YORK CITY. Therefore, even if we concede that not all speakers have the same mastery of the concept of New York City, we can attribute to them attitudes to propositions formed of that concept. It is sufficient that they master partially the constitutive use of the proper name 'New York City' and defer in their use of it to the expert members of their community.

\section{Finally, I address argument (2). Schiffer writes:}

It is widely believed that names and other singular terms rigidly designate their referents, and this affects the truth conditions of propositions referred to by that-clauses containing those rigid designators, so that, for example, the propositions Ralph believes when he believes that George Eliot was a man is one that is true in any arbitrary possible world just in case George Eliot exists and is a man in that world. How, one may wonder, can the Fregean assign the right possible-worlds truth conditions to the proposition that George Eliot was a man, given that for him, the 
Fregean, the referent of the that-clause occurrence of 'George Eliot' is not George Eliot but rather a concept of her (Schiffer 2003: 24-25).

Schiffer challenges the Fregean model to explain how propositions get their truth conditions. When propositions are thought of as Russellian propositions made out of objects, properties and relations the problem of determining their truth conditions seems to have a solution at hand. Let $\left\langle\left\langle a_{1} \ldots a_{n}\right\rangle R^{n}\right\rangle$ be a Russellian propositions; then $\left\langle\left\langle a_{1}\right.\right.$ $\left.\left.\ldots a_{n}\right\rangle R^{n}\right\rangle$ is true if and only if $\left\langle a_{1} \ldots a_{n}\right\rangle$ instantiates $R^{n}$. But when propositions are thought of as Fregean propositions, how, Schiffer says, can we determine their truth conditions?

The issue that Schiffer addresses by this question concerns the relation of determination between concepts and the referents they are about. A widespread interpretation of the notion of determination regards it as satisfaction of predicative content. This means that in order for a thing to be determined by a concept, that thing must satisfy the condition fixed by the concept. Suppose the concept expressed by 'George Eliot' fixes the condition of being the author of The Mill on the Floss. Then, a thing must be the author of The Mill on the Floss in order to be thought of by grasping that concept.

Concepts are ways of thinking of objects, properties and relations. As noted in section $\S 5$, Fregean propositions might be regarded as ways of thinking of Russellian propositions. Accordingly, Fregean propositions would inherit their truth conditions from the Russellian propositions they determine. In case a Fregean proposition is made out of concepts without referents, then no Russellian proposition is determined and the Fregean proposition is either false or truthvalueless. For example, the Fregean propositions $\left\langle\mathrm{C}_{\text {Geroge Eliot }}, \mathrm{C}_{\text {being a }}\right.$ ${ }_{\text {man }}$ ) determines the Russellian proposition 〈Mary Anne Evans, the property of being a man $\rangle$ that is truth if and only if Mary Anne Evans instantiates the property of being a man. By contrast the Fregean proposition $\left\langle\mathrm{C}_{\text {Pegasus }}, \mathrm{C}_{\text {flying }}\right\rangle$ does not determine any Russellian proposition and, consequently, it is either false or truth-valueless.

This view would offer a solution to the problem of determining the truth conditions of Fregean propositions. But, were this the only solution, then the Fregean model would be in trouble. Indeed, Schiffer seems to have precisely this difficulty in mind ${ }^{11}$. The problem is that this widespread interpretation of the notion of determination falls

\footnotetext{
${ }^{11}$ Cf. Schiffer (2003: 34).
} 
prey to Kripke's arguments against descriptivism. In fact, if determination were satisfaction of predicative content, then the Fregean proposition $\left\langle\mathrm{C}_{\text {Geroge Eliot }}, \mathrm{C}_{\text {being a man }}\right\rangle$ would determine different Russellian propositions in different possible worlds. As a consequence, it would inherit different truth conditions in different possible worlds. For example, in a possible world $\mathrm{W}$ in which James Joyce wrote The Mill on the Floss the concept $\mathrm{C}_{\text {Geroge Eliot }}$ would determine James Joyce and the proposition $\left\langle\mathrm{C}_{\text {Geroge Eliot }}, \mathrm{C}_{\text {being a man }}\right\rangle$ would be true in that world. But the intuition behind referential rigidity, to which Schiffer seems to appeal in his objection, suggests that if one has a belief whose content is the proposition $\left\langle\mathrm{C}_{\text {Geroge Eliot }}, \mathrm{C}_{\text {being a man }}\right\rangle$, then he has a belief that is true if and only if Mary Anne Evans was a man. This belief is false in all possible worlds, or at least in all possible worlds in which Mary Anne Evans existed.

The notion of concept fills three function ${ }^{12}$ : concept $_{1}$ : representing the mode in which objects, properties and relations are thought of; concept $t_{2}$ : determining the objects, properties and relations that are thought of; concept $t_{3}$ : providing entities to be referred to in indirect contexts, namely the building blocks of propositions. Reflections on rigid designations show that no entity can covers all three functions if determination is shaped in terms of satisfaction of predicative content. One might protest and defend the exegetical claim that Frege had in mind just satisfaction of predicative content when he said that senses determine referents. I will not enter this exegetical dispute. The purpose of this paper is to defend the Fregean model of propositions resumed by points (A), (B) and (C) in section $\S 1$. My claim is that the acceptance of these points does not commit us to the notion of determination as satisfaction of predicative content.

To answer Schiffer's objection, we have to show that the claim that singular terms express concepts is consistent with the claim that singular terms designate rigidly their referents. According to the theory of concepts suggested in section $\S 4$, concepts are constituted by basic regularities of use of expressions. More precisely, a concept expressed by an expression $\mathrm{w}$ is constituted by acceptance conditions of certain sentences containing w. As to singular terms, for instance

${ }^{12}$ Cf. Burge (1977: 356). 
proper names, the following are examples of acceptance conditions that might be concept-constitutive ${ }^{13}$ :

'NN', expressing the concept it does consists in speakers' acceptance of ' $\# \mathrm{NN}$ '.

where ' $\# \mathrm{NN}$ ' is some collection of sentences containing 'NN' such as, say, 'this is NN' (when acquainted with $\mathrm{NN}$ ), 'NN is the $\varphi$ ', 'NN is F'.

The acceptance conditions of these sentences fix certain propername-using practices. As Gareth Evans holds ${ }^{14}$, such sentences vehicle information about the referents of the proper name. But in order for an objet to be the referent of a proper name, it is not necessary that such information be true of the object. It is true that the information associated to a proper-name-using practice is relevant in determining to which object the proper name refers. But it is so because such information individuates the concept expressed, and therefore the proper name itself when it is taken not merely as a string of sign or sounds. This means that if speakers accept the sentence 'NN is the $\varphi$ ', it is not correct to conclude that they use ' $\mathrm{NN}$ ' to refer to the object that satisfies the definite description expressed by 'the $\varphi$ '. The fact that speakers accept the sentence ' $N N$ is the $\varphi$ ' shows that they are involved in a certain proper-name-using practice and, as a consequence, that they attach a certain concept to ' $\mathrm{NN}$ '. Nevertheless, it might turn out that the sentence ' $\mathrm{NN}$ is the $\varphi$ ' vehicle a piece of misinformation. All the information that a proper-name-using practice associates to a proper name might be false. Thus, the information expressed by the concept-constitutive sentences is relevant for determining to which proper-name-using practice the speakers participate not for identifying the referents of the proper names used. Or more precisely, it is relevant for determining which are their referents only in a derivative way, namely by determining the propername-using practices.

In conclusion, although ' $\mathrm{NN}$ ' expresses a concept, nothing prevents us from treating it as a rigid designator. It is consistent with 'NN', expressing a concept to hold that 'NN' refers to $\mathrm{NN}$ in all

${ }^{13}$ Cf. Evans (1982: 376-78). See also Horwich (1998: 126).

${ }^{14}$ In this paragraph I follow Evans' view on proper names (1982: ch. 11). See also Sainsbury 2001. 
possible worlds. For example, 'George Eliot' expresses a concept and it might be constitutive of that concept to accept the sentence 'George Eliot is the author of The Mill on the Floss'. But the referent of 'George Eliot' is Goerge Eliot, alias Mary Anne Evans, in all possible worlds, even in those in which James Joyce wrote The Mill on the Floss. The semantic value of 'George Eliot' remains constant in all possible worlds. This view copes with the intuitions about rigid designation according to which the proposition expressed by 'George Eliot is a man' is false even in those possible worlds in which James Joyce wrote The Mill on the Floss.

One might object that this is only half a solution of the problem of determining the truth conditions of Fregean propositions. Although the claim that singular terms express concepts can be proved to be consistent with the claim that singular terms denote rigidly their referents, it must be explained how the truth conditions of Fregean propositions are determined.

Which notion of determination is invoked in the claim that concepts determine referents? My contention is that a functional notion of determination provides a satisfactory answer to this question. Concepts determine referents in the sense that two expressions with the same concept-constitutive regularities of use are co-extensional. In this sense, the extension of an expression is a function of the concept it expresses. This is the idea of determination advocated by deflationary theories of reference and truth. Deflationary theories take Condition $\mathrm{T}$ to be a sufficient condition for a theory of truth to be adequate ${ }^{15}$. Convention $\mathrm{T}$ states that an account of truth is materially adequate if it implies $\mathrm{T}$-sentences in which the sentences used in the right-hand side are the translations of the sentences quoted in the left-hand side. The notion of translation involves the notion of concept. A correct translation from language L into language L' maps Lexpressions onto L'-expressions that express the same concepts. Thus, the notion of concept is in play in the selection of the relevant instances of T-schema (or equivalently of the instances of the reference-schema for singular terms, the instances of the applicationschema for predicates and the instances of the satisfaction-schema for expressions standing for functions). In this sense, extensions are function of concepts and concepts fills the function concept $t_{2}$.

\footnotetext{
${ }^{15}$ For a discussion of this point see Patterson 2002.
} 
I recognise that the functional sense of determination of referents by concepts poses a commitment to deflationism. However, Schiffer does not provide any criticism of deflationism. On the contrary he seems to appeal to some deflationary intuition when he provides the somethingfrom-nothing transformations that introduce pleonastic propositions.

\author{
Massimiliano Vignolo \\ Dipart. di Filosofia, Università di Genova \\ via Balbi 4, 16126 Genova, Italy \\ maxi@nous.unige.it
}

\title{
References
}

Burge, Tyler. 1977. Belief de re. Journal of Philosophy 74: 338-63.

Burge, Tyler. 1979. Frege and the Hierarchy. Synthese 40: 265-81.

Burge, Tyler. 2005. Postscript to 'Frege and the Hierarchy'. In T. Burge, Truth, Thought, Reason: Essays on Frege. Oxford: Oxford University Press, 2005: 167-210.

Cozzo, Cesare. 1994. Meaning and Argument. Stockholm: Almqvist \& Wiksell International, 1994.

Davidson, Donald. 1965. Theories of Meaning and Learnable Languages. In Y. Bar-Hillel (ed.), Proceeding's of the 1964 Congress for Logic, Methodology, and Philosophy of Science. Amsterdam: North-Holland Publishing Company. Repr. in his Inquiries into Truth and Meaning. Oxford: Oxford University Press, 1984: 3-15.

Dummett, Michael. 1973. Frege: Philosophy of Language. London: Duckworth, 1973.

Evans, Gareth. 1982. The Varieties of Reference. Oxford: Oxford University Press, 1982.

Horwich, Paul. 1998. Meaning. Oxford: Clarendon Press, 1998.

Kaplan, David. 1969. Quantifying In. In D. Davidson and J. Hintikka, (eds.), Words and Objections. Dordrecht: Reidel, 1969: 206-42.

Künne, Wolfgang. 1997. First Person Propositions: A Fregean Account. In W. Künne, A. Newen, M. Anduschus (eds.) Direct Reference, Indexicality, and Propositional Attitudes. Stanford: CSLI Publications, 1997: 49-67.

McDowell, John. 1984. De Re Senses. The Philosophical Quarterly 34: 283-94.

Parson, Terence. 1981. Frege's Hierarchies of Indirect Sense and the Paradox of Analysis. Midwest Studies in Philosophy 6: 37-57.

Patterson, Douglas. 2002. Theories of Truth and Convention T. Philosophers' Imprint 2: 1-16.

Peacocke, Christopher. 1996. Entitlement, Self-Knowledge and Conceptual Redeployment. Proceedings of the Aristotelian Society 96: 117-58. 
Sainsbury, Mark. 2001. Sense Without Reference. In A. Newen, U. Nortman, R. Stuhlmann-Laeisz (eds.) Building on Frege. Stanford: CSLI Publications, 2001: 211-30.

Schiffer, Stephen. 1992. Belief Ascription. Journal of Philosophy 89: 499-521.

Schiffer, Stephen. 1994. A Paradox of Meaning. Nous 28: 279-324.

Schiffer, Stephen. 2003. The Things We Mean. Oxford: Clarendon Press, 2003.

Zalta, Edward. 1989. Singular Propositions, Abstract Constituents, and Propositional Attitudes. In J. Almog, J. Perry, H. Wettstein (eds.) Themes from Kaplan. Oxford Oxford: University Press, 1989: 455-78.

Zalta, Edward. 1993. Replies to the Critics. Philosophical Studies 69: 231-42.

Zalta, Edward. 2001. Fregean Senses, Modes of Presentations, and Concepts. Philosophical Perspectives 15: 335-59. 